\title{
Autologous bone marrow stem cell therapy for patients undergoing coronary artery bypass grafting: A meta-analysis of 14 randomized controlled trials
}

\author{
SHANLIAN WU ${ }^{1-4^{*}}$, LIANG YAO ${ }^{3 *}$, PEIJING YAN ${ }^{3}$, QIANGWEI BAO ${ }^{1,2}$, XIN DONG $^{5}$, XINGGUANG LIU $^{6}$, \\ $\mathrm{YAN} \mathrm{ZHU}^{7}, \mathrm{XIN} \mathrm{SU}^{7,8}, \mathrm{AQIAN} \mathrm{WANG}^{7,8}, \mathrm{YICHAO} \mathrm{DUAN}^{7}, \mathrm{KEHU} \mathrm{YANG}^{3,4}$, MIN ZHANG ${ }^{2}$ and $\mathrm{YUNSHAN} \mathrm{CAO}^{7}$ \\ ${ }^{1}$ Department of Pathology, School of Basic Medicine, Gansu University of Chinese Medicine; ${ }^{2}$ Department of Pathology, \\ Gansu Provincial Hospital; ${ }^{3}$ Institute of Clinical Research and Evidence-Based Medicine, Gansu Provincial Hospital; \\ ${ }^{4}$ Department of Evidence-Based Medicine Center, School of Basic Medical Sciences, Lanzhou University, Lanzhou, \\ Gansu 730000; ${ }^{5}$ Department of Ultrasound, The Third Hospital of Gansu Province, Lanzhou, Gansu 730020; \\ Departments of ${ }^{6}$ Cardiac Surgery and ${ }^{7}$ Cardiology, Gansu Provincial Hospital; ${ }^{8}$ Department of Cardiology, \\ School of Clinical Medicine, Gansu University of Chinese Medicine, Lanzhou, Gansu 730000, P.R. China
}

Received July 10, 2018; Accepted January 24, 2019

DOI: $10.3892 /$ etm.2019.7283

\begin{abstract}
Autologous bone marrow stem cell (BMSC) therapy is a novel option for regenerative therapy in patients with ischemic heart disease. The aim of the present meta-analysis was to evaluate the effectiveness of BMSCs combined with coronary artery bypass grafting (CABG). The PubMed, Cochrane Library, EMBASE and Web of Science databases were searched from inception to November 22, 2017 for randomized controlled trials on BMSC therapy combined with CABG. Finally, 14 trials with a total of 596 participants were included. Data were analyzed using a random-effects model. Compared with the control group, the BMSC therapy group exhibited an improvement in the left ventricular (LV) ejection fraction from baseline to follow-up [mean difference $(\mathrm{MD})=4.36 \% ; 95 \%$ confidence interval $(\mathrm{CI})$ : $1.90-6.81 \% ; \mathrm{P}<0.01]$. Analysis of the pooled results revealed non-significant differences in the LV end-diastolic volume ( $\mathrm{MD}=-6.27 \mathrm{ml}$; 95\% CI: -22.34 to $9.80 \mathrm{ml} ; \mathrm{P}=0.44), \mathrm{LV}$ end-diastolic volume index $\left(\mathrm{MD}=-15.11 \mathrm{ml} / \mathrm{m}^{2} ; 95 \% \mathrm{CI}\right.$ : -31.53 to $\left.1.30 \mathrm{ml} / \mathrm{m}^{2} ; \mathrm{P}=0.07\right), \mathrm{LV}$ end-systolic volume
\end{abstract}

Correspondence to: Dr Min Zhang, Department of Pathology, Gansu Provincial Hospital, 204 Donggang West Road, Lanzhou, Gansu 730000, P.R. China

E-mail: sallyzhangmin@126.com

Dr Yunshan Cao, Department of Cardiology, Gansu Provincial Hospital, 204 Donggang West Road, Lanzhou, Gansu 730000, P.R. China

E-mail: yunshancao@126.com

*Contributed equally

Key words: bone marrow, stem cell, coronary artery bypass, meta-analysis, randomized controlled trial
$(\mathrm{MD}=-11.52 \mathrm{ml} ; 95 \% \mathrm{CI}:-26.97$ to $3.93 \mathrm{ml} ; \mathrm{P}=0.14)$ and $\mathrm{LV}$ end-systolic volume index $\left(\mathrm{MD}=-16.56 \mathrm{ml} / \mathrm{m}^{2}\right.$; $95 \%$ CI: -37.75 to $4.63 \mathrm{ml} / \mathrm{m}^{2} ; \mathrm{P}=0.13$ ) between the BMSC and CABG alone groups. Therefore, autologous BMSC therapy for patients undergoing CABG appears to be associated with an improvement in LV function compared with CABG alone.

\section{Introduction}

Ischemic heart disease (IHD) remains the leading cause of morbidity and mortality worldwide $(1,2)$. Ischemic injury to the heart muscle often results in irreversible loss of myocardial tissue, with ensuing impairment of left ventricular (LV) function. In addition to medical treatment and surgical or interventional revascularization methods, there is currently a considerable number of studies on autologous bone marrow stem cell (BMSC) therapy in combination with coronary artery bypass grafting (CABG) in the treatment of IHD (3-16). BMSC therapy is aimed at repairing the damaged myocardium, preventing ventricular remodeling and improving overall cardiac function (17).

In clinical studies, the use of BMSCs is the most popular cardiac cell-based therapy. This may be due to the fact that BMSCs are easier to obtain compared with other stem cells (e.g., circulating stem cells and cardiac stem cells), and their preparation does not require prolonged ex vivo manipulation (18). Although recent studies demonstrated that catheter-based cell delivery (e.g., NOGA ${ }^{\mathrm{TM}}$ mapping) enables increased myocardial retention of cells, this method may not be feasible in certain patients with peripheral vascular disease (19). Therefore, injection of BMSCs is a good option for patients undergoing $\mathrm{CABG}$.

However, the efficacy of CABG in combination with BMSC therapy remains controversial. It has been demonstrated that CABG combined with BMSC therapy is beneficial for cardiac function, without any adverse effects, and is therefore a safe and feasible adjunct therapy in clinical practice $(3,4,13,16)$. 
However, other studies reported that CABG combined with BMSC therapy had no effect on global LV function and clinical symptoms (5,7).

Several previous meta-analyses on CABG combined with BMSC therapy either had certain methodological limitations or included an insufficient number of studies (20-22). In addition, since the publication of those meta-analyses, several new randomized controlled trials (RCTs) have been published $(3,13,15)$. Hence, the present meta-analysis was performed to re-evaluate the effectiveness of CABG combined with BMSC therapy.

\section{Materials and methods}

Trial search. The PubMed, Cochrane Library, EMBASE and Web of Science databases were searched from inception to November 22, 2017, using the key words 'bone marrow cells OR s'tem cells' OR 'cell' OR 'progenitor cell' OR 'stem cell transplantation' OR 'cell transplantation' OR 'bone marrow transplantation' OR 'stromal cells' and 'coronary artery bypass' OR 'coronary artery bypass grafting' OR 'Myocardial Revascularization'. There were no language restrictions.

Inclusion criteria. Studies were included based on the following criteria: i) Participants with a clinical diagnosis of chronic IHD; ii) RCTs comparing CABG in combination with BMSC therapy and CABG alone for chronic IHD; iii) follow-up for at least 3 months after stem cell therapy.

Exclusion criteria. The exclusion criteria were as follows: i) Non-RCTs; ii) catheter-based stem cell injection methods; iii) stem cells derived from sources other than the bone marrow (e.g., c-kit ${ }^{+}$cardiac stem cells); iv) participants with a clinical diagnosis of acute myocardial infarction; v) stem cell injection without CABG; and vi) studies with incomplete LV function data.

Risk of bias assessment. The methodological quality of the selected RCTs was independently assessed by 2 researchers (SW and LY) based on the Cochrane risk of bias criteria (23), and each quality item was rated as low-risk, high-risk or unclear-risk. The 7 items used to evaluate bias in each trial included random sequence generation, allocation concealment, blinding of participants and personnel, blinding of outcome assessment, incomplete outcome data and selective reporting.

Data extraction. Two reviewers (SW and LY) independently extracted the following relevant data from each study: First author; year of publication; country of origin; study population, including treatment and control group; participant characteristics, including age and sex; follow-up time; type of stem cells; dose of stem cells; route of stem cell administration; outcome measurement method; LV ejection fraction (LVEF), including baseline $\left(\mathrm{LVEF}_{\text {baseline }}\right)$, follow-up $\left(\mathrm{LVEF}_{\text {follow-up }}\right)$, and LVEF change from baseline to follow-up for the treatment $\left(\mathrm{LVEF}_{\mathrm{BMSC}}\right.$ change) and control groups $\left(\mathrm{LVEF}_{\text {control change }}\right) ; \mathrm{LV}$ end-diastolic volume (LVEDV), including baseline $\left(\mathrm{LVEDV}_{\text {baseline }}\right)$, follow-up ( $\mathrm{LVEDV}_{\text {follow-up }}$ ), and LVEDV change from baseline to follow-up for the treatment $\left(\mathrm{LVEDV}_{\text {BMSC change }}\right)$ and control groups ( $\left.\mathrm{LVEDV}_{\text {control change }}\right) ; \mathrm{LV}$ end-systolic volume (LVESV), including baseline (LVESV $\left.V_{\text {baseline }}\right)$, follow-up (LVESV $\left.V_{\text {follow-up }}\right)$, and LVESV change from baseline to follow-up for the treatment $\left(\operatorname{LVESV}_{\text {BMSC change }}\right)$ and control groups ( LVESV $\left._{\text {control change }}\right)$; LV end-diastolic volume index (LVEDVI), including baseline $\left(\mathrm{LVEDVI}_{\text {baseline }}\right)$, follow-up (LVEDVI $\left.\mathrm{L}_{\text {follow-up }}\right)$, and LVEDVI change from baseline to follow-up for the treatment (LVEDVI $\left.I_{\text {BMSC change }}\right)$ and control groups (LVEDVI $\left.I_{\text {control change }}\right)$; and LV end-systolic volume index (LVESVI), including baseline (LVESVI baseline $\left._{\text {e }}\right)$ and follow-up (LVESVI follow-up $)$, and LVESVI change from baseline to follow-up for the treatment (LVESVI $\left.I_{\text {BMSC change }}\right)$ and control groups (LVESVI $\left.I_{\text {control change }}\right)$. Any disagreements between the reviewers were resolved by reaching a consensus.

Statistical analysis. The statistical analysis software R, version 3.4.2 was used to analyze the data. A meta-analysis was performed to calculate the mean difference (MD) $\mathrm{LVEF}_{\text {change }}\left(\mathrm{MD} \mathrm{LVEF} \mathrm{F}_{\text {change }}=\mathrm{LVEF}_{\text {BMSC change }}-\mathrm{LVEF}_{\text {control change }}\right.$,

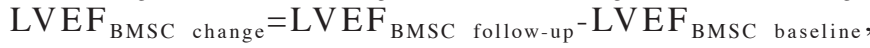
$\mathrm{LVEF}_{\text {control change }}=\mathrm{LVEF}_{\text {control follow-up }}-\mathrm{LVEF}_{\text {control baseline }}$, and simi-

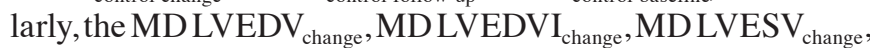
and MD LVESVI $I_{\text {change }}$, as well as their $95 \%$ confidence intervals (CIs). The majority of the studies reported the mean and standard deviation (SD). In one study (3), LV volume and ejection fraction values were expressed as mean and standard error (SE). The SE was converted into the SD by appling the formula $\mathrm{SD}=\mathrm{SE} \sqrt{n}$, where $\mathrm{n}$ is the sample size. In two studies $(4,7)$, the $\mathrm{LV}$ volume and ejection fraction values were expressed as the median and interquartile range. Median and interquartile range were converted into the mean and SD using the method introduced by Hozo et al (24).

In addition, the mean and SD of the $\mathrm{LVEF}_{\mathrm{BMSC}}$ change and $\mathrm{LVEF}_{\text {control change }}$ were not directly reported by certain studies $(3,5,6,9,10,12,13,15,16)$. The mean of the $\operatorname{LVEF}_{\text {BMSC change }}$ and $\mathrm{LVEF}_{\text {control change }}$ may be easily obtained by calculating the difference between the means of the $\mathrm{LVEF}_{\text {baseline }}$ and $\mathrm{LVEF}_{\text {follow-up. }}$. However, the SD of the $\mathrm{LVEF}_{\mathrm{BMSC}}$ change and $\mathrm{LVEF}_{\text {control change }}$ may only be effectively calculated from the $\mathrm{LVEF}_{\text {baseline }}$ and $\mathrm{LVEF}_{\text {follow-up }}$ values if the value of the correlation coefficient (Corr) is known. Therefore, the SD of $\mathrm{LVEF}_{\mathrm{BMSC}}$ change and $\mathrm{LVEF}_{\text {control change }}$ in the study by Hendrikx et al (11) were used to calculate the Corr values by using the following formula:

$$
\text { Corr }=\frac{S D_{\text {baseline }}^{2}+S D_{\text {follow-up }}^{2}-S D_{\text {change }}^{2}}{2 \times S D_{\text {baseline }} \times S D_{\text {follow-up }}}
$$

The calculation yielded Corr $=0.6$ for the BMSC and the control groups. The SD of $\mathrm{LVEF}_{\mathrm{BMSC}}$ change and $\mathrm{LVEF}_{\text {control change }}$ was calculated by inputting these values in the following formula:

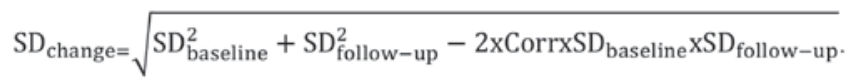

The mean and SD of the LV volume change values were calculated in the same manner.

A random-effects model was used to pool the data, and statistical heterogeneity between summary data was evaluated using $\mathrm{I}^{2}$ statistics. Egger's test was applied to examine publication bias. All tests were two-tailed and $\mathrm{P}<0.05$ was considered to indicate a statistically significant difference. 
Subgroup analysis. To evaluate whether the effectiveness of CABG combined with BMSC therapy in ischemic heart disease patients was influenced by the clinical characteristics, subgroup analyses were performed based on i) follow-up time ( $>6$ or $\leq 6$ months); ii) method to determine the outcome measure [echocardiography or cardiac magnetic resonance imaging (cMRI)]; iii) type of stem cells [bone marrow mononuclear cells (BMMNCs) or other selected cell populations (CD133+ and CD34+ cells)]; iv) route of injection [intramyocardial (IM) or intracoronary (IC)]; v) dose of stem cells [ $\geq 10^{8}$ or $<10^{8}$ cells $\left(10^{8}\right.$ was the median number of BMSCs injected)]; vi) baseline LVEF $\leq 35$ or $>35 \%$ ( $35 \%$ was the median LVEF at baseline in the included studies). Analyses were performed to evaluate whether the differences between the subgroups were statistically significant.

Sensitivity analysis. Sensitivity analysis was performed by excluding low-quality studies, trials recruiting participants with particular conditions or trials with characteristics different from the others. A sensitivity analysis of the primary outcome LVEF was performed.

\section{Results}

Search results. A total of 1,785 studies were identified from the electronic database search. Deduplication and removal of all clearly irrelevant studies excluded 151 articles. Initial screening of the remaining 1,627 studies against the inclusion criteria excluded a further 1,602 studies (animal experiments, case reports, meeting abstracts, insufficient data and reviews). In the remaining 23 studies, the full text was assessed for eligibility, subsequently excluding 9 studies: 2 studies used c-kit ${ }^{+}$cardiac stem cells rather than BMSCs, 4 studies did not provide complete LV function data, 2 studies were replicated and no CABG was performed in 1 study. The final analysis included 14 independent RCTs. A flow chart depicting the study selection process is presented in Fig. 1.

Study characteristics. A total of 14 studies met the inclusion criteria for the present meta-analysis, including a total of 596 participants who were assessed for the primary outcomes of the study. The 'treatment group' ( $n=316)$ included participants who had received CABG combined with BMSC therapy, while the 'control group' $(n=280)$ included patients who had only received CABG. The mean follow-up period was 11 months. The mean age of the participants ranged from 53.8 to 66.8 years, and the percentage of male patients ranged from 70 to $100 \%$. A total of 5 studies were performed in China, 2 in Germany and 1 each in the USA, UK, Canada, Serbia, Finland, France and Belgium; the Canadian study was a multicenter trial (15 patients in Montreal and 18 in Toronto) (3). The baseline characteristics of the included studies are summarized in Table I.

Risk of bias assessment. Of the 14 studies, $9(64.2 \%)$ adequately generated their randomisation sequence, 5 (35\%) concealed allocation, $7(50 \%)$ blinded participants and personnel, $6(42.9 \%)$ blinded outcome assessment and 6 studies had a low risk of bias regarding selective reporting. All of the studies had a low risk of bias regarding missing outcome data. The detailed information on risk of bias is provided in Figs. 2 and 3.

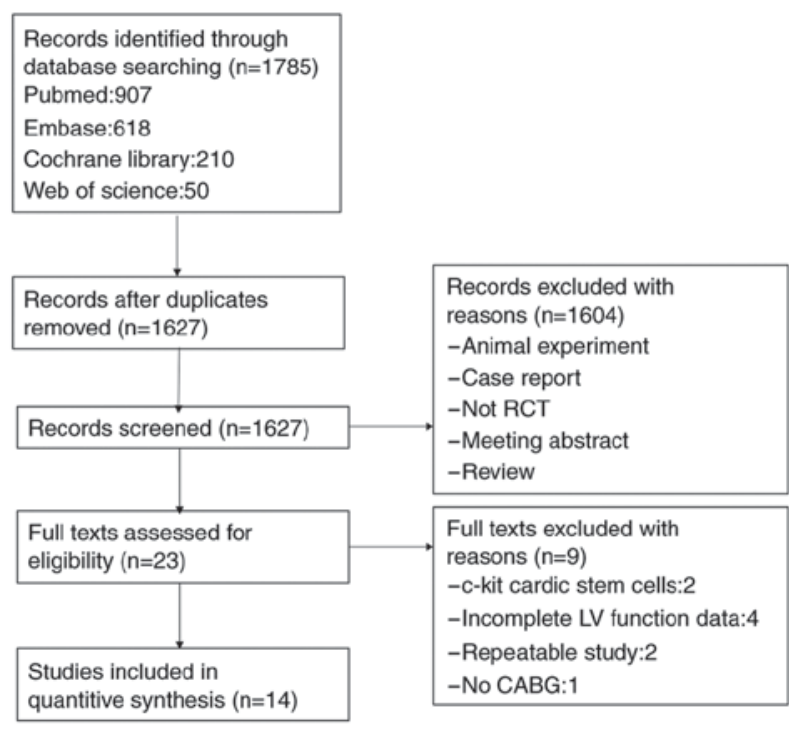

Figure 1. Flow diagram of included studies. RCT, randomized controlled trial; CABG, coronary artery bypass grafting; LV, left ventricle.

$L V E F_{\text {change }}$. All 14 studies, including a total of 537 participants, reported on the change in LVEF after the treatment. In the treatment group, the mean change in the LVEF from baseline to follow-up was $8.46 \%$. In the control group, the mean change in the LVEF from baseline to follow-up was $4.22 \%$. The difference in the change of the LVEF between the treatment and control groups was statistically significant $(\mathrm{MD}=4.36 \%$; 95\% CI: 1.90-6.81\%; P<0.01; Fig. 4).

$L V E D V_{\text {change. }}$ A total of 7 studies with 224 participants reported on the change in LVEDV after the treatment. There was no significant difference in the overall change of LVEDV from baseline to follow-up between the treatment and control groups $(\mathrm{MD}=-6.27 \mathrm{ml}$; 95\% CI: -22.34 to $9.80 \mathrm{ml}$; $\mathrm{P}=0.44$; Fig. 5).

$L V E D V I_{\text {change }}$. A total of 4 studies with 159 participants reported on the change in LVEDVI after the treatment. There was no significant difference in the overall change of LVEDVI from baseline to follow-up between the treatment and control groups $\left(\mathrm{MD}=-15.11 \mathrm{ml} / \mathrm{m}^{2}\right.$; $95 \% \mathrm{CI}$ : -31.53 to $1.30 \mathrm{ml} / \mathrm{m}^{2}$; $\mathrm{P}=0.07$; Fig. 6).

$L V E S V_{\text {change }}$. A total of 5 studies with 156 participants reported a change in LVESV after the treatment. There was no significant difference in the overall change of LVESV from baseline to follow-up between the treatment and control groups ( $\mathrm{MD}=-11.52 \mathrm{ml}$; 95\% CI: -26.97 to $3.93 \mathrm{ml}$; $\mathrm{P}=0.14$; Fig. 7 ).

$L V E S V I_{\text {change }}$. A total of 4 studies with 159 participants reported a change in LVESVI after the treatment. There was no significant difference in the overall change of LVESVI from baseline to follow-up between the treatment and control groups $\left(\mathrm{MD}=-16.56 \mathrm{ml} / \mathrm{m}^{2} ; 95 \% \mathrm{CI}:-37.75\right.$ to $4.63 \mathrm{ml} / \mathrm{m}^{2}$; $\mathrm{P}=0.13$; Fig. 8).

Publication bias. To exclude potential publication bias, funnel plots (Fig. 9) and Egger's test for publication bias was performed. No publication bias was evident for the 14 studies 


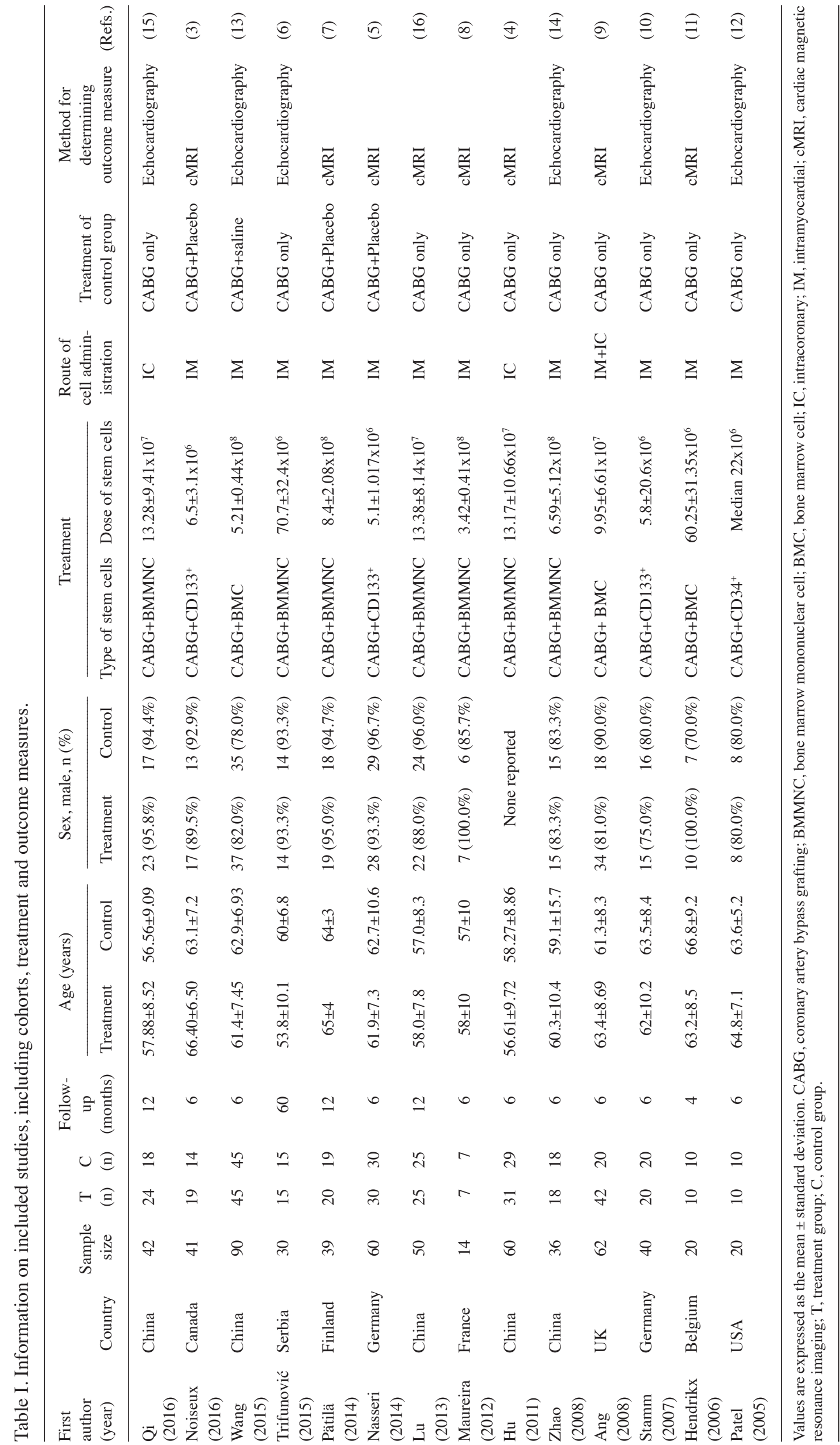


Random sequence generation (selection bias)

Allocation concealment (selection bias)

Blinding of participants and personnel (performance bias)

Blinding of outcome assessment (detection bias)

Incomplete outcome data (attrition bias)

Selective reporting (reporting bias)

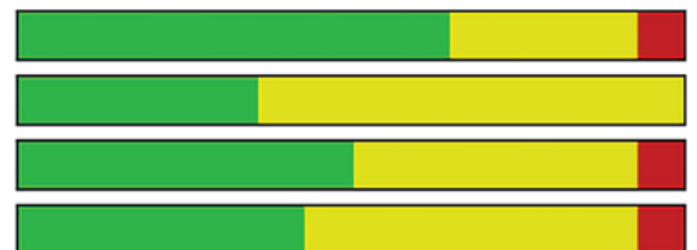

Other bias

Low risk of bias

$0 \%$

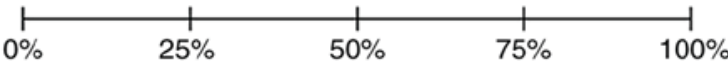

$\square$ High risk of bias

Figure 2. Risk of bias graph. The authors' judgement regarding each risk of bias item is presented as percentages across all included studies.

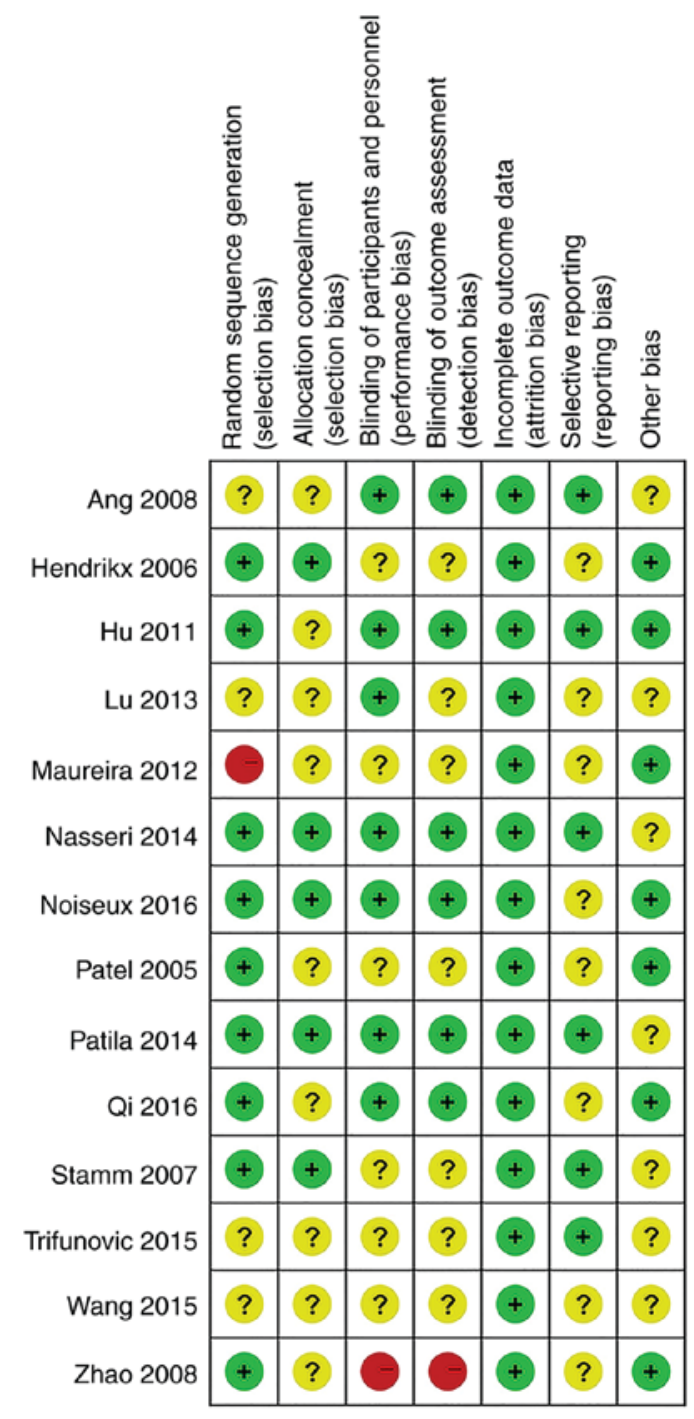

Figure 3. Risk of bias summary: Authors' judgement regarding each risk of bias item for each of the studies included.

included in the LVEF meta-analysis (Egger's test $\mathrm{P}=0.48$ for the $\mathrm{MD}$ of $\left.\mathrm{LVEF}_{\text {change }}\right)$.
Subgroup analysis. The subgroup analysis did not reveal any significant differences within subgroups based on follow-up period, type of stem cells, route of cell administration, dose of stem cells and baseline LVEF (Table II). However, the measurement method for the LVEF (echocardiography or cMRI) affected the effectiveness of CABG combined with BMSC injection in IHD patients $(\mathrm{P}<0.01$; Table II).

Sensitivity analysis. A sensitivity analysis, in which the trials with relatively low-quality data by Maureira et al (8) and Zhao et al (14) were excluded, indicated that the results were not markedly affected by the exclusion $\left[\mathrm{LVEF}_{\text {change }}\right.$ $(\mathrm{MD}=4.01 \%$; 95\% CI: 1.47-6.56\%; $\mathrm{P}<0.01)]$.

\section{Discussion}

The present meta-analysis demonstrated that BMSC therapy may improve cardiac function during $\mathrm{CABG}$ in patients with IHD. The change of LVEF from baseline to follow-up in the treatment group (CABG + BMSCs) increased by $4.36 \%$ compared with that in the control group (CABG alone). The $\mathrm{LVESV}_{\text {change }}$ and $\mathrm{LVEDV}_{\text {change }}$ were reduced in the treatment group, but the difference from the control group was not statistically significant. Sensitivity analyses that excluded low-quality studies and studies that only included patients with particular medical conditions did not alter these results. Furthermore, these results were generally consistent, regardless of the follow-up time, type of stem cells, route of cell injection (IM or IC), dose of stem cells and baseline LVEF. However, the difference in the measurement method of LVEF (echocardiography or cMRI) affected the results $(\mathrm{P}<0.0001)$.

At present, the mechanisms of the efficacy of BMSC therapy in patients undergoing $\mathrm{CABG}$ remains elusive, and it may be multifactorial. Certain studies suggested that BMSCs may exert their beneficial effect by paracrine stimulation, cell fusion and transdifferentiation (25-28). Rota et al (29) demonstrated in rats that c-kit ${ }^{+}$BMSCs engraft in proximity to the infarcted myocardium and differentiate into cells of the cardiogenic lineage, forming functionally competent cardiomyocytes and vascular structures. In addition, the effect of certain cytokines, 


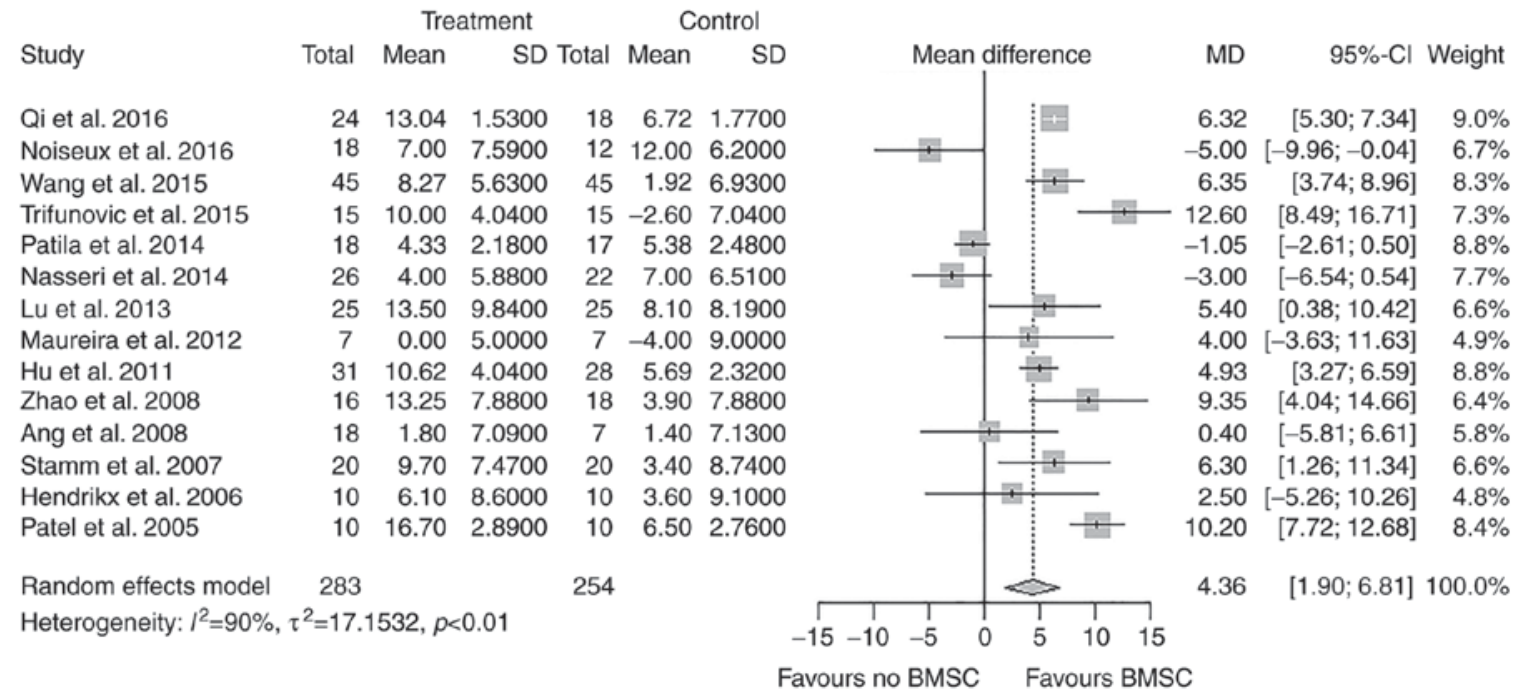

Figure 4. Forest plot of the difference in the change from baseline in the left ventricular ejection fraction between the treatment and control groups. Grey boxes represent the weight of the study; diamonds indicate the combined results of the effect size of each study; the data-points represent the mean difference value; horizontal lines represent the 95\% CI; CI, confidence interval; MD, mean difference; SD, standard deviation; BMSC, bone marrow stem cell.

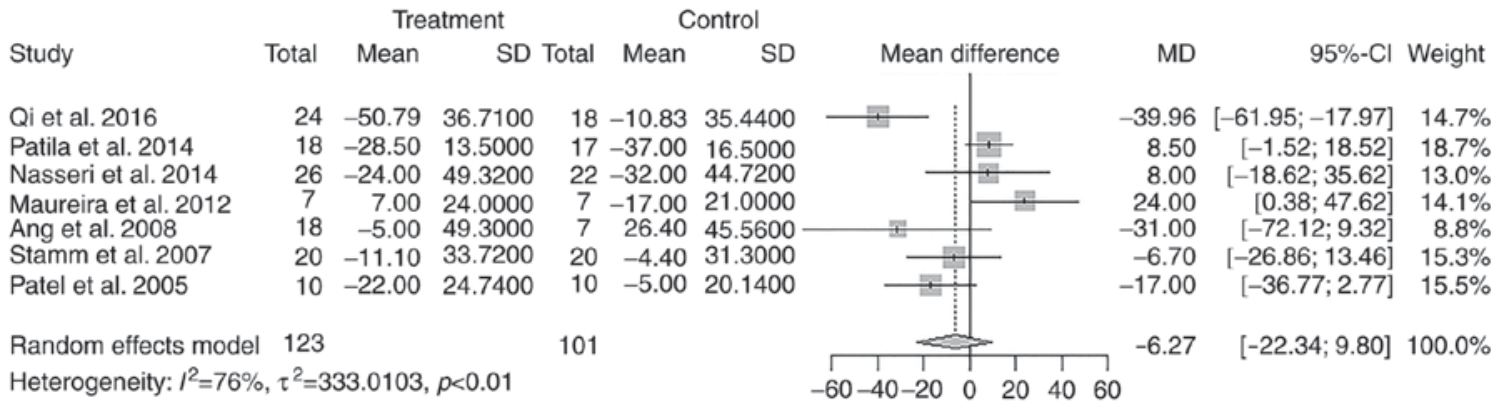

Favours BMSC Favours no BMSC

Figure 5. Forest plot of the difference in the change from baseline in left ventricular end-diastolic volume $(\mathrm{ml})$ between the treatment group and control group. Grey boxes represent the weight of the study; diamonds indicate the combined results of the effect size of each study; the data-points represent the mean difference value; horizontal lines represent the $95 \% \mathrm{CI}$; CI, confidence interval; MD, mean difference; SD, standard deviation; BMSC, bone marrow stem cell.

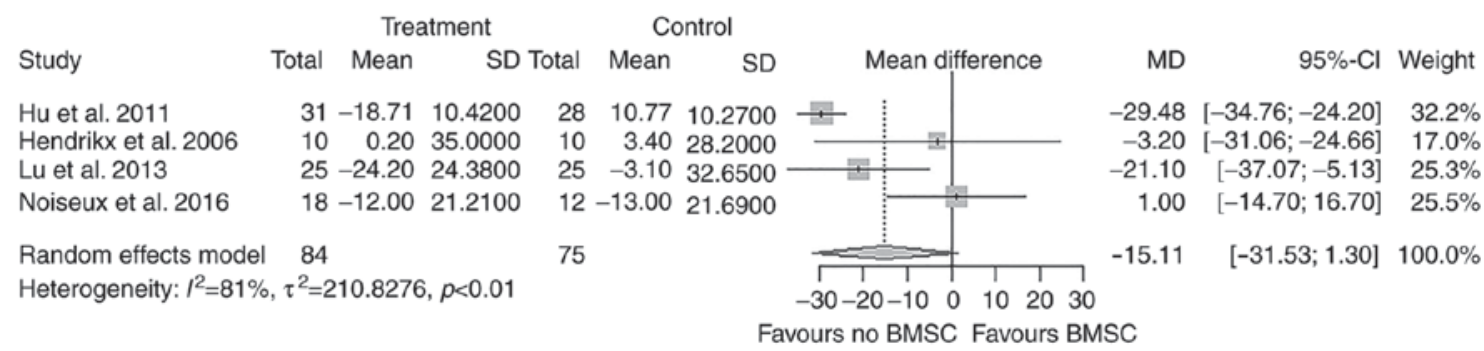

Figure 6. Forest plot of the difference in the change from baseline in the left ventricular end-diastolic volume index between the treatment group and the control group $\left(\mathrm{ml} / \mathrm{m}^{2}\right)$. Grey boxes represent the weight of the study; diamonds indicate the combined results of the effect size of each study; the data-points represent the mean difference value; horizontal lines represent the 95\% CI; CI, confidence interval; MD, mean difference; SD, standard deviation; BMSC, bone marrow stem cell.

including vascular endothelial growth factor (VEGF), has been indicated to restore coronary vessels and myocytes via angiogenesis following experimental infarction. BMSCs express a number of cytokines, including VEGF, insulin-like growth factor and platelet-derived growth factor, which stimulate the regeneration and proliferation of residual normal myocytes and intrinsic myocardial stem cells (endogenous stem cells) for cell regeneration and fusion $(30,31)$.
In the present meta-analysis, 10 studies provided short-term follow-up ( $\leq 6$ months) and 4 studies reported long-term follow-up ( $>6$ months) data, but only 1 study provided 5-year follow-up data. There was no significant difference regarding the improvement in the LVEF between the short-term and long-term follow-up. A systematic review and meta-analysis by Jeevanantham et al (32) indicated that adult BMSC therapy improves the LVEF in patients with IHD compared with 


\begin{tabular}{|c|c|c|c|c|c|c|c|c|c|c|}
\hline \multirow[b]{2}{*}{ Study } & \multirow[b]{2}{*}{ Total } & \multicolumn{3}{|c|}{ Treatment } & \multicolumn{2}{|c|}{ Control } & \multirow[b]{2}{*}{ Mean difference } & \multirow[b]{2}{*}{ MD } & \multirow[b]{2}{*}{$95 \%-\mathrm{Cl}$} & \multirow[b]{2}{*}{ I Weight } \\
\hline & & Mean & SD & Cotal & Mean & SD & & & & \\
\hline Qi et al. 2016 & 24 & -44.00 & 28.3100 & 18 & -11.38 & 25.3400 & 1 & -32.62 & {$[-48.91 ;-16.33]$} & $22.9 \%$ \\
\hline Patila et al. 2014 & 18 & -26.75 & 12.2500 & 17 & -28.25 & 21.2500 & & 1.50 & {$[-10.08 ;$} & $26.2 \%$ \\
\hline Maureira et al. 2012 & 7 & 4.00 & 20.0000 & 7 & -2.00 & 25.0000 & 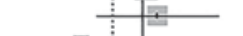 & 6.00 & {$[-17$} & $17.8 \%$ \\
\hline $\begin{array}{l}\text { Ang et al. } 2008 \\
\text { Stamm et al. } 2007\end{array}$ & 18 & -6.10 & 45.5000 & 7 & -17.50 & 45.3200 & 一 & -23.60 & {$[-63.21 ; 16.01]$} & $10.2 \%$ \\
\hline Stamm et al. 2007 & 20 & -19.10 & 24.8400 & 20 & -5.50 & 27.9600 & & -13.60 & {$[-29.99 ; 2.79]$} & $22.8 \%$ \\
\hline landom effects model & 87 & & & 69 & & & & -11.52 & {$[-26.97 ; 3.93]$} & $100.0 \%$ \\
\hline Heterogeneity: I & $=20$ & 01 & & & & & urs BMSC Fav & ISC & & \\
\hline
\end{tabular}

Figure 7. Forest plot of the difference in the change from baseline in the left ventricular end-systolic volume (ml) between the treatment group and the control group. Grey boxes represent the weight of the study; diamonds indicate the combined results of the effect size of each study; the data-points represent the mean difference value; horizontal lines represent the $95 \% \mathrm{CI}$; CI, confidence interval; MD, mean difference; SD, standard deviation; BMSC, bone marrow stem cell.

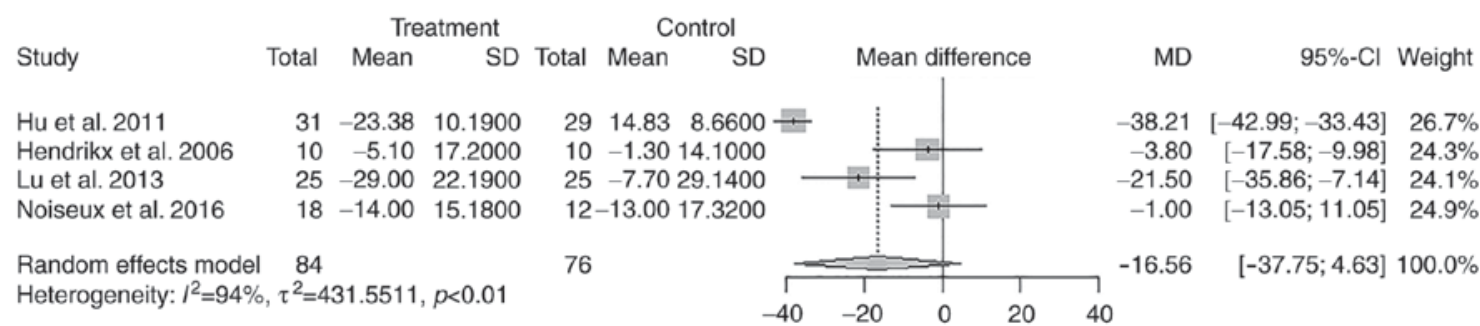

Figure 8. Forest plot of the difference in the change from baseline in the left ventricular end-systolic volume index between the treatment and control groups $\left(\mathrm{ml} / \mathrm{m}^{2}\right)$. Grey boxes represent the weight of the study; diamonds indicate the combined results of the effect size of each study; the data-points represent the mean difference value; horizontal lines represent the 95\% CI; CI, confidence interval; MD, mean difference; SD, standard deviation; BMSC, bone marrow stem cell.

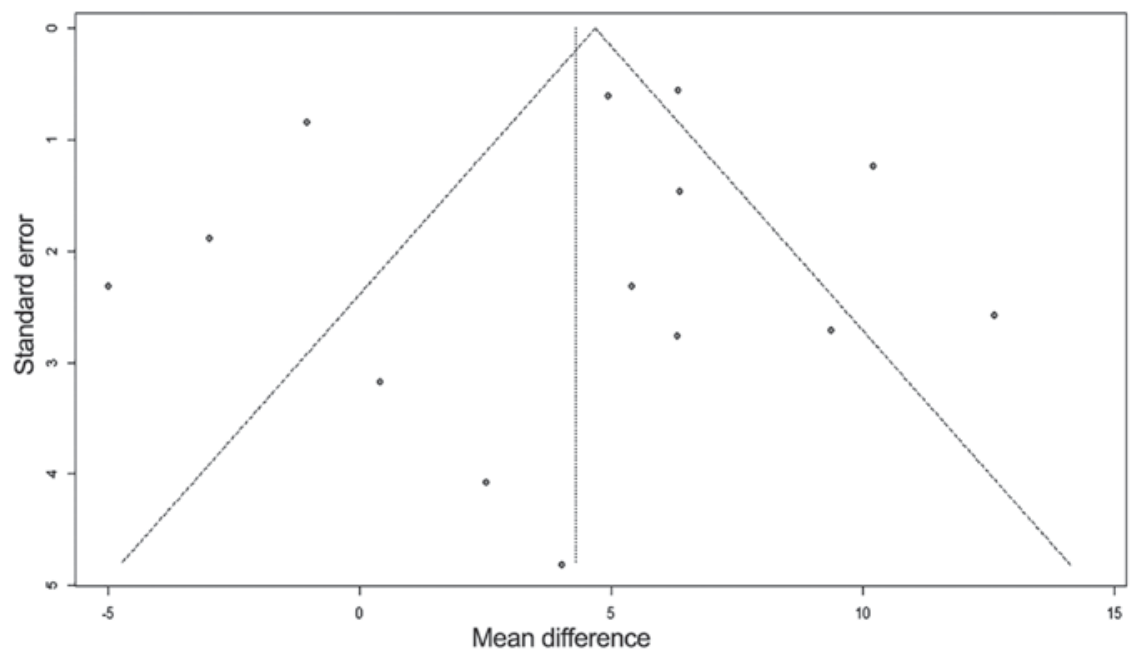

Figure 9. Funnel plot of the difference in the change from baseline in the left ventricular ejection fraction in treatment and control groups.

standard treatment, and these benefits persist at least beyond 24 months (32). Similarly, Nesteruk et al (33) indicated that the LVEF in the stem cell therapy group improved at 5 years compared with that in the CABG alone group. These data suggest that the benefits of BMSC therapy on cardiac function are not short-lived.

With regard to the methods for measuring the LVEF (echocardiography or cMRI), the subgroup analysis demonstrated that the choice of method affected the determined effectiveness of CABG combined with BMSC injection in IHD patients $(\mathrm{P}<0.0001)$. cMRI and echocardiography have important diagnostic value in assessing cardiac function, and perform similarly regarding the method of calculaton in the measurement of the cardiac ejection fraction. However, echocardiographic measurements may be affected by the ultrasonographer, whereas MRI is more reliable and accurate for measuring cardiac function.

Regarding the type of BMSC therapy, 2 of the 4 studies that included $\mathrm{CD}_{133^{+}}$or $\mathrm{CD} 34^{+}$cells in the meta-analysis had an unfavorable MD. However, only 1 of the 10 studies using BMMNCs/BMCs had an unfavorable MD. These results suggest that using BMMNCs/BMCs may lead to a more noticeable improvement in the LVEF compared with $\mathrm{CD}_{133^{+}}$or CD $34^{+}$cells. However, this result may be limited by the small sample size of the cohort treated with $\mathrm{CD} 133^{+}$or $\mathrm{CD} 34^{+}$cells, and accordingly, the conclusions may only be preliminary. 
Table II. Subgroup analysis of LVEF change for each variable.

\begin{tabular}{|c|c|c|c|}
\hline Variable & No. of trials & $\mathrm{MD}(95 \% \mathrm{CI})$ & P-value \\
\hline \multicolumn{4}{|c|}{ Follow-up for examining LVEF (months) } \\
\hline$>6$ & 4 & $5.61(0.34-10.89)$ & \multirow[t]{2}{*}{0.56} \\
\hline$\leq 6$ & 10 & $3.81(0.78-6.83)$ & \\
\hline \multicolumn{4}{|c|}{ Method of measurement } \\
\hline Echocardiography & 6 & $8.26(6.15-10.36)$ & \multirow[t]{2}{*}{$<0.0001$} \\
\hline $\mathrm{cMRI}$ & 8 & $0.86(-2.19-3.90)$ & \\
\hline \multicolumn{4}{|l|}{ Type of stem cells } \\
\hline BMMNC & 7 & $5.73(2.46-9.01)$ & \multirow[t]{2}{*}{0.42} \\
\hline $\mathrm{CD}_{133}{ }^{+} / \mathrm{CD} 34^{+}$ & 4 & $2.21(-5.69-10.12)$ & \\
\hline \multicolumn{4}{|c|}{ Route of cell administration } \\
\hline IC & 2 & $5.79(4.46-7.11)$ & \multirow[t]{2}{*}{0.47} \\
\hline IM & 11 & $4.35(0.67-8.03)$ & \\
\hline \multicolumn{4}{|c|}{ Amount of stem cells administered } \\
\hline$\geq 10^{8}$ & 7 & $4.84(1.95-7.73)$ & \multirow[t]{2}{*}{0.69} \\
\hline$<10^{8}$ & 7 & $3.56(-1.96-9.08)$ & \\
\hline \multicolumn{4}{|l|}{ Baseline LVEF (\%) } \\
\hline$\leq 35$ & 6 & $4.49(1.65 ; 7.34)$ & \multirow[t]{2}{*}{0.97} \\
\hline$>35$ & 8 & $4.39(0.10 ; 8.68)$ & \\
\hline
\end{tabular}

LVEF, left ventricular ejection fraction; cMRI, cardiac magnetic resonance imaging; BMMNC, bone marrow mononuclear cells; IC, intracoronary; IM, intramyocardial; MD, mean difference ('effect size' for the treatment vs. control group); CI, confidence interval.

Autologous cell preparations are medical products characterized by complexity in terms of differences in cell isolation protocols and storage of cell products, and the methods for assessing outcome may be inhomogeneous. These factors may affect the role of $\mathrm{CD}_{133^{+}}$or $\mathrm{CD} 34^{+}$cell therapy in improving cardiac function. Therefore, the function of $\mathrm{CD}_{133}{ }^{+}$or $\mathrm{CD} 34^{+}$ cells in improving LVEF and the underlying mechanisms and remain to be further elucidated.

A total of 3 previous meta-analyses (20-22) have analyzed the effect of CABG in combination with BMSC therapy in patients with IHD. The present results differ from those of the previous meta-analyses in several aspects. In the meta-analysis study by Donndorf et al (22) reported that the improvement in the LVEF (MD of $\mathrm{LVEF}_{\text {change }}$ of $5.40 \%$ ) tended to be more prominent; however, their study only included 6 trials (4 RCTs and 2 cohorts; Table III presents the studies that were included in previous meta-analyses) with a total of 179 patients, whereas the present study included 14 RCTs with a total of 596 participants. Therefore, the present results may be more reliable. The meta-analysis by Qin et al (20) indicated that BMSC therapy significantly improved the LVEF and reduced the LVEDV and LVESV; however, their study only indicated the MD of the post-treatment LVEF values between the BMSC and the CABG alone groups, whereas in the present meta-analysis, the MD of LVEF change from follow-up to baseline between the BMSC and CABG groups was calculated. Therefore, the present results may be more reliable. Ali-Hassan-Sayegh et al (21), who included 9 studies (6 RTCs and 3 cohorts) with a total of 335 patients, obtained similar results compared with the present meta-analysis for the
$\mathrm{LVEF}_{\text {change }}(\mathrm{MD}=4.06 \%, 95 \% \mathrm{CI}: 0.41$ to $7.72 \%$; $\mathrm{P}<0.01)$ and $\mathrm{LVEDV}_{\text {change }}(\mathrm{MD}=7.06 \mathrm{ml}, 95 \% \mathrm{CI}: 8.58$ to $22.7 \mathrm{ml}$; $\mathrm{P}=0.30)$. Our study demonstrated, with markedly narrower CIs, that CABG in combination with BMSC therapy may improve cardiac function. Compared with the previous meta-analysis studies, a large number of additional studies was included and more thorough analyses were performed. The addition of large RCTs provided more reliable estimates of the effects of CABG combined with BMSC therapy. Furthermore, the LVEDVI and LVESVI were only determined in 4 trials included in the present study $(3,4,11,16)$. Although this is a small sample, these indexes are more reflective regarding the heart function compared with LVEDV and LVESV, as each individual's body surface area is different. In addition, the majority of the studies reported on the LVEDV and LVESV as clinical outcomes, so their data were extracted separately. This may be one of the reasons for the difference in LVEDV and LVESV not being statistically significant. Therefore, future meta-analyses must include more studies to obtain significant results.

The present meta-analysis was based on a comprehensive search strategy, including a systematic rigorous approach to the evaluation of RCTs investigating the effectiveness of BMSC therapy in combination with CABG in IHD patients. A detailed subgroup analysis was performed to explore differences in $\mathrm{LVEF}_{\text {change. }}$. Although the results of the present study appear promising regarding the efficacy of BMSC therapy, there were also certain limitations: First, there was significant heterogeneity in the present meta-analysis, which may be attributable to the dose and type of BMSC therapy, the timing 
Table III. Comparison of studies included in the previous meta-analyses.

\begin{tabular}{|c|c|c|c|c|}
\hline Study (years) & $\begin{array}{l}\text { Meta-analysis by } \\
\text { Qin et al (20) }\end{array}$ & $\begin{array}{c}\text { Meta-analysis by } \\
\text { Donndorf et al (22) }\end{array}$ & $\begin{array}{l}\text { Meta-analysis by } \\
\text { Ali-Hassan-Sayegh et al (21) }\end{array}$ & (Refs.) \\
\hline Qi et al (2016) & No & No & No & $(15)$ \\
\hline Noiseux et al (2016) & No & No & No & (3) \\
\hline Wang et al (2015) & No & No & No & (13) \\
\hline Trifunović et al (2015) & No & No & No & (6) \\
\hline Pätilä et al (2014) & No & No & No & (7) \\
\hline Nasseri et al (2014) & No & No & Yes & $(5)$ \\
\hline Lu et al (2013) & Yes & No & No & $(16)$ \\
\hline Maureira et al (2012) & Yes & No & No & (8) \\
\hline Hu et al (2011) & Yes & No & No & (4) \\
\hline Zhao et al (2008) & Yes & Yes & Yes & $(14)$ \\
\hline Ang et al (2008) & Yes & No & Yes & (9) \\
\hline Stamm et al (2007) & No & Yes & Yes & $(10)$ \\
\hline Hendrikx et al (2006) & Yes & Yes & Yes & (11) \\
\hline Patel et al (2005) & No & Yes & Yes & (12) \\
\hline
\end{tabular}

Yes refers to the studies that were included in the present study that were also included in previous respective meta-analyses. No refers to the studies that were included in the present study, but were not included in the previous respective meta-analyses.

of CABG combined with BMSC therapy after myocardial ischemia, the baseline LVEF, method of cell processing and outcome measurement methods, and these factors may affect the efficacy of BMSC therapy. Furthermore, the CIs were relatively wide, most likely due to the small number of studies and the relatively sparse subjects in all outcomes. Finally, the follow-up was relatively short in most studies, and the sustained efficacy of BMSC therapy for patients undergoing CABG remains to be further demonstrated. The results of the present meta-analysis should be confirmed in large, adequately powered RCTs assessing the efficacy of BMSC therapy, and outcome measures should be standardised (e.g. LVEF, LVEDV and LVESV). Future research should also focus on the mechanisms of action of BMSC therapy to further confirm the results of meta-analyses in IHD patients.

In conclusion, based on the present evidence, autologous BMSC therapy for patients undergoing CABG appears to be associated with an improvement in LV function. This improvement is beyond that achieved by CABG alone. Therefore, BMSC therapy may be beneficial as an adjuvant therapy for patients undergoing $\mathrm{CABG}$.

\section{Acknowledgements}

Not applicable.

\section{Funding}

This study was supported by the National Natural Science Foundation of China (grant no. 81770300), the International Cooperation Exchange Project of Gansu province (grant no. 18YF1WA046), the Science and Technology Projects of Lanzhou, China (grant no. 2016-2-57) and CAS 'Light of West China' Program granted to MZ.

\section{Availability of data and materials}

All the datasets generated and analyzed during the present study are available from the corresponding author on reasonable request.

\section{Authors' contributions}

SW and LY analyzed the patient data and were the major contributors in the preparation of the manuscript. QB and AW analyzed part of the patient data. XS and YD performed the literature search and extracted the data. XD and XL were responsible for the statistical analysis. YZ, PY and KY made substantial contributions to the conception of the study. MZ and YC drafted the manuscript. All the authors have read and approved the final version of this manuscript.

\section{Ethics approval and consent to participate}

Not applicable.

\section{Patient consent for publication}

Not applicable.

\section{Competing interests}

The authors declare that they have no competing interests to disclose.

\section{References}

1. Townsend N, Nichols M, Scarborough P and Rayner M: Cardiovascular disease in Europe-epidemiological update 2015. Eur Heart J 36: 2696-2705, 2015. 
2. Writing Group Members, Mozaffarian D, Benjamin EJ, Go AS, Arnett DK, Blaha MJ, Cushman M, Das SR, de Ferranti S, Després JP, et al: Heart Disease and Stroke Statistics-2016 update: A report from the American Heart Association. Circulation 133: e38-e360, 2016.

3. Noiseux N, Mansour S, Weisel R, Stevens LM, Der Sarkissian S, Tsang K, Crean AM, Larose E, Li SH, Wintersperger B, et al: The IMPACT-CABG trial: A multicenter, randomized clinical trial of $\mathrm{CD} 133^{+}$stem cell therapy during coronary artery bypass grafting for ischemic cardiomyopathy. J Thorac Cardiovasc Surg 152: $1582-1588,2016$

4. Hu S, Liu S, Zheng Z, Yuan X, Li L, Lu M, Shen R, Duan F, Zhang $\mathrm{X}, \mathrm{Li} \mathrm{J}$, et al: Isolated coronary artery bypass graft combined with bone marrow mononuclear cells delivered through a graft vessel for patients with previous myocardial infarction and chronic heart failure: A single-center, randomized, double-blind placebo-controlled clinical trial. J Am Coll Cardiol 57: 2409-2415, 2011.

5. Nasseri BA, Ebell W, Dandel M, Kukucka M, Gebker R, Doltra A, Knosalla C, Choi YH, Hetzer R and Stamm C: Autologous CD133' bone marrow cells and bypass grafting for regeneration of ischaemic myocardium: The Cardio133 trial. Eur Heart J 35: 1263-1274, 2014.

6. Trifunović Z, Obradović S, Balint B, Ilić R, Vukić Z, Šišić M, Kostić J, Rusović S, Dobrić M and Ostojić G: Functional recovery of patients with ischemic cardiomyopathy treated with coronary artery bypass surgery and concomitant intramyocardial bone marrow mononuclear cell implantation-a long-term follow-up study. Vojnosanit Pregl 72: 225-232, 2015.

7. Pätilä T, Lehtinen M, Vento A, Schildt J, Sinisalo J, Laine M, Hämmäinen P, Nihtinen A, Alitalo R, Nikkinen P, et al: Autologous bone marrow mononuclear cell transplantation in ischemic heart failure: A prospective, controlled, randomized, double-blind study of cell transplantation combined with coronary bypass. J Heart Lung Transplant 33: 567-574, 2014

8. Maureira P, Tran N, Djaballah W, Angioï M, Bensoussan D, Didot N, Fay R, Sadoul N, Villemot JP and Marie PY: Residual viability is a predictor of the perfusion enhancement obtained with the cell therapy of chronic myocardial infarction: A pilot multimodal imaging study. Clin Nucl Med 37: 738-742, 2012

9. Ang KL, Chin D, Leyva F, Foley P, Kubal C, Chalil S, Srinivasan L, Bernhardt L, Stevens S, Shenje LT and Galiñanes M: Randomized, controlled trial of intramuscular or intracoronary injection of autologous bone marrow cells into scarred myocardium during CABG versus CABG alone. Nat Clin Pract Cardiovasc Med 5: 663-670, 2008

10. Stamm C, Kleine HD, Choi YH, Dunkelmann S, Lauffs JA, Lorenzen B, David A, Liebold A, Nienaber C, Zurakowski D, et al: Intramyocardial delivery of $\mathrm{CD}_{133^{+}}$bone marrow cells and coronary artery bypass grafting for chronic ischemic heart disease: Safety and efficacy studies. J Thorac Cardiovasc Surg 133: 717-725, 2007.

11. Hendrikx M, Hensen K, Clijsters C, Jongen H, Koninckx R, Bijnens E, Ingels M, Jacobs A, Geukens R, Dendale P, et al: Recovery of regional but not global contractile function by the direct intramyocardial autologous bone marrow transplantation: Results from a randomized controlled clinical trial. Circulation 114 (Suppl 1): I101-I107, 2006.

12. Patel AN, Geffner L, Vina RF, Saslavsky J, Urschel HC Jr, Kormos R and Benetti F: Surgical treatment for congestive heart failure with autologous adult stem cell transplantation: A prospective randomized study. J Thorac Cardiovasc Surg 130: 1631-1638, 2005.

13. Wang H, Wang Z, Jiang H, Ma D, Zhou W, Zhang G, Chen W, Huang $J$ and Liu Y: Effect of autologous bone marrow cell transplantation combined with off-pump coronary artery bypass grafting on cardiac function in patients with chronic myocardial infarction. Cardiology 130: 27-33, 2015.

14. Zhao Q, Sun Y, Xia L, Chen A and Wang Z: Randomized study of mononuclear bone marrow cell transplantation in patients with coronary surgery. Ann Thorac Surg 86: 1833-1840, 2008.

15. Qi Z, Liu S, Lv X, Duan F, Wang H, Gao Y and Wang J: Effects of bone marrow mononuclear cells delivered through a graft vessel for patients with previous myocardial infarction and chronic heart failure: An echocardiographic study of left atrium function. Echocardiography 33: 1835-1843, 2016

16. Lu M, Liu S, Zheng Z, Yin G, Song L, Chen H, Chen X, Chen Q, Jiang S, Tian L, et al: A pilot trial of autologous bone marrow mononuclear cell transplantation through grafting artery: A sub-study focused on segmental left ventricular function recovery and scar reduction. Int J Cardiol 168: 2221-2227, 2013.
17. Strauer BE and Steinhoff G: 10 years of intracoronary and intramyocardial bone marrow stem cell therapy of the heart: From the methodological origin to clinical practice. J Am Coll Cardiol 58: 1095-1104, 2011.

18. Tongers J, Losordo DW and Landmesser U: Stem and progenitor cell-based therapy in ischaemic heart disease: Promise, uncertainties, and challenges. Eur Heart J 32: 1197-1206, 2011.

19. Banovic M, Ostojic MC, Bartunek J, Nedeljkovic M, Beleslin B and Terzic A: Brachial approach to NOGA-guided procedures: Electromechanical mapping and transendocardial stem-cell injections. Tex Heart Inst J 38: 179-182, 2011.

20. Qin SL, He CY, Xu JS, Lai XY, Liu SS and He WP: Meta-analysis of coronary artery bypass graft surgery combined with stem cell transplantation in the treatment of ischemic heart diseases. Coron Artery Dis 26: 170-175, 2015.

21. Ali-Hassan-Sayegh S, Mirhosseini SJ,Lotfaliani MR, Dehghan HR, Sedaghat-Hamedani F, Kayvanpour E, Rezaeisadrabadi M, Ghaffari N, Vahabzadeh V, Jebran AF, et al: Transplantation of bone marrow stem cells during cardiac surgery. Asian Cardiovasc Thorac Ann 23: 363-374, 2015.

22. Donndorf P, Kundt G, Kaminski A, Yerebakan C, Liebold A, Steinhoff $G$ and Glass A: Intramyocardial bone marrow stem cell transplantation during coronary artery bypass surgery: A meta-analysis. J Thorac Cardiovasc Surg 142: 911-920, 2011.

23. Higgins JPT and Green S (eds): Cochrane Handbook for Systematic Reviews of Interventions version 5.1.0 [updated March 2011]. The Cochrane Collaboration, 2011. Available from http://handbook. cochrane.org.

24. Hozo SP, Djulbegovic B and Hozo I: Estimating the mean and variance from the median, range, and the size of a sample. BMC Med Res Methodol 5: 13, 2005.

25. Duran JM, Makarewich CA, Sharp TE, Starosta T, Zhu F, Hoffman NE, Chiba Y, Madesh M, Berretta RM, Kubo H, et al: Bone-derived stem cells repair the heart after myocardial infarction through transdifferentiation and paracrine signaling mechanisms. Circulation research 113: 539-552, 2013.

26. Li TS, Cheng K, Malliaras K, Smith RR, Zhang Y, Sun B, Matsushita N, Blusztajn A, Terrovitis J, Kusuoka H, et al: Direct comparison of different stem cell types and subpopulations reveals superior paracrine potency and myocardial repair efficacy with cardiosphere-derived cells. J Am Coll Cardiol 59: 942-953, 2012.

27. Yoon CH, Koyanagi M, Iekushi K, Seeger F, Urbich C, Zeiher AM and Dimmeler S: Mechanism of improved cardiac function after bone marrow mononuclear cell therapy: Role of cardiovascular lineage commitment. Circulation 121: 2001-2011, 2010.

28. Li SH, Sun Z, Brunt KR, Shi X, Chen MS, Weisel RD and Li RK: Reconstitution of aged bone marrow with young cells repopulates cardiac-resident bone marrow-derived progenitor cells and prevents cardiac dysfunction after a myocardial infarction. Eur Heart J 34: 1157-1167, 2013.

29. Rota M, Kajstura J, Hosoda T, Bearzi C, Vitale S, Esposito G, Iaffaldano G, Padin-Iruegas ME, Gonzalez A, Rizzi R, et al: Bone marrow cells adopt the cardiomyogenic fate in vivo. Proc Natl Acad Sci USA 104: 17783-17788, 2007.

30. Beohar N, Rapp J, Pandya S and Losordo DW: Rebuilding the damaged heart: The potential of cytokines and growth factors in the treatment of ischemic heart disease. J Am Coll Cardiol 56: 1287-1297, 2010.

31. Alvarez-Dolado M, Pardal R, Garcia-Verdugo JM, Fike JR, Lee HO, Pfeffer K, Lois C, Morrison SJ and Alvarez-Buylla A: Fusion of bone-marrow-derived cells with Purkinje neurons, cardiomyocytes and hepatocytes. Nature 425: 968-973, 2003.

32. Jeevanantham V, Butler M, Saad A, Abdel-Latif A,Zuba-Surma EK and Dawn B: Adult bone marrow cell therapy improves survival and induces long-term improvement in cardiac parameters: A systematic review and meta-analysis. Circulation 126: 551-568, 2012.

33. Nesteruk J, Voronina N, Kundt G, Donndorf P, Klopsch C, Kaminski A, Duckers HJ and Steinhoff G: Stem cell registry programme for patients with ischemic cardiomyopathy undergoing coronary artery bypass grafting: What benefits does it derive? ESC Heart Fail 4: 105-111, 2017.

This work is licensed under a Creative Commons Attribution-NonCommercial-NoDerivatives 4.0 International (CC BY-NC-ND 4.0) License. 